\title{
The development of an instructional design model as a strategic enabler for sustainable competitive advantage
}

\author{
L. Le Roux and H. Oosthuizen* \\ University of Stellenbosch Business School, University of Stellenbosch, \\ PO Box 610, Bellville 7535, Republic of South Africa \\ ho2@usb.ac.za
}

Received February 2010

\begin{abstract}
In a business environment of continuous change and in light of a defined need to fast track skills improvement in South Africa and Africa, training strategies and practices are under increasing pressure to develop a more productive and skilled workforce. Demands on training and the practices it employs increasingly focus on the alignment with strategic imperatives of organisations.
\end{abstract}

\begin{abstract}
This research presented an instructional design (ID) model positioned in the intersection between the positioning-based and resource-based theories and used a multi-disciplinary approach to extend the literature on ID models and offer measurable improvements in job-specific knowledge and productive behaviour as proxies for sustainable competitive advantage. The research confirmed the contribution of the ID model in this regard and described and substantiated the pivotal link between training and ID models and the application thereof in practice to aid organisations in the achievement and sustainability of competitive advantage. In this, the second article, the ID model will be subjected to empirical investigation and evaluated through the application thereof in a case organisation and a grounded conclusion provided. Hence, this article presents a brief overview of the first article, and focuses on the research methodology, research results, analysis and interpretation; conclusions and assessment of the research.
\end{abstract}

This is the second in a series of two articles

*To whom all correspondence should be addressed.

\section{Introduction}

The first article in this series presented the context for the research and was defined as being situated in the prevailing volatile and changing external and internal environments that organisations operate in that demand relevant jobspecific knowledge and productive behaviour from the workforce to contribute to superior organisational performance. One way to engender and improve productive behaviour is through training, and specifically the development and implementation of instructional design (ID) models aimed at making a measurable impact on the job-specific knowledge and productive behaviour of the workforce as well as being aligned to the strategic imperatives of the organisation.

The research is positioned in the resource-based view (RBV) and the positioning-based view (PBV) of the organisation and the intersection between these views in the sustainable competitive advantage (SCA) offered when an organisation achieves differentiation through the special skills, distinctive competencies and productive behaviour vested in and exhibited by employees. The PBV is relevant in that it describes the value of differentiation as a strategic option, while the RBV provides the theoretical framework for the ID model and its role as a strategic enabler in the organisation.
The capabilities and competencies of an organisation are brought about through, amongst others, the job-specific knowledge and productive behaviour of the employees of the organisation.

Strategically, training practices, or as in the instance of this research the ID model employed to implement the training, need to demonstrably affect behaviour of the workforce and outcomes for the organisation. The ID model presented in this research aimed at improving job-specific knowledge and productive behaviour as proxies for SCA and thus the research endeavour was to evaluate the impact of the proposed ID model on these proxies.

\section{Structure of the article}

The article will be presented in three sections. First, the research methodology, including the research approach and research programme will be outlined; secondly the results, analysis and interpretation will be presented; and thirdly conclusions and an assessment of the research will be offered. The article will be concluded with a summary. 


\section{Research methodology}

"Research methodology refers to the procedural framework within which the research is conducted. It describes an approach to a problem that can be put into practice in a research programme or process” (Remenyi et al., 2002:28).

The procedural framework of this research consists of a description of the research approach, which includes the research aim and purpose, philosophical orientation and research tactic; and the research programme, which includes the research methods, data analysis and data integrity measures.

\section{Research approach}

The research approach includes the research aim and research purpose, the philosophical orientation and the research tactic.

\section{- $\quad$ Research aim}

The main aim of the research was to evaluate the ID model and to provide an explanation of the internal construct relationships between the influence of the ID model and jobspecific knowledge and productive behaviour. Specifically, the Kirkpatrick $(1994 ; 1996)$ model of evaluation, a standard learning evaluation tool in business and industry (Bassi, Benson \& Cheney, 1996; Boyle \& Crosby, 1997) was applied.

This main aim of the research was underpinned by specific research goals (aligned to the Kirkpatrick model measurements), namely to investigate reactions to the ID model; to determine levels of learning and job-specific knowledge improvement brought about by the ID model; to analyse the impact of the ID model on job-specific knowledge application; to evaluate the performance of the ID model and to understand how and why (if) the ID model was seen to work. Linked to these research goals were the action standards of the research, specified as to obtain a positive reaction to the ID model; to bring about a measurable increase in job-specific knowledge and improvement in the application thereof in the way the workforce executed their jobs; and to obtain positive ratings for the components of the ID model.

\section{- $\quad$ Research purpose}

Since the ID model as presented had not been implemented in any organisation previously, and the link between the ID model and SCA were explored, the nature of the research was by necessity exploratory, in that it gathered explanations and aimed to gain insight into a phenomenon about which little is known (the ID model) through openended, largely unstructured methods (Denzin \& Lincoln, 1994; Hesse-Biber \& Leavy, 2004) in order to gain a clear understanding of the research issue at hand. Exploratory research seeks to develop insight and understanding (i.e. why and how the ID model works), but does not seek to test them. It aims to identify key understandings and relationships for further investigation, since it was difficult to determine (at the stage of the application of the ID model) what was relevant. The purpose of the research was therefore to discover, identify, describe and explain what makes a complex social situation (i.e. the ID model) workable or not. Due to its exploratory and interpretive nature no claim is made about statistical generalisations or predictive capabilities of this research. However, case studies, when backed up by the literature, are transferable to theoretical propositions. Inductive support, obtained through deductive reasoning based on the theoretical propositions in the literature, enables the transferability of case study research (Mouton, 1996:80).

\section{- $\quad$ Philosophical orientation}

The philosophical orientation defines the underlying basis or paradigm used for constructing a research investigation. It outlines the basic belief system of the researcher and comprises "an accepted set of theories, methods and ways of defining data” (Hussey \& Hussey, 1997:47). For many years (and, in many academic quarters, to this day), a philosophical debate raged about which of two strategies, positivism or interpretivism, is the most appropriate to study the social world (Burrell \& Morgan, 1979; Guba, 1985; Hammersley, 2000). The main tenet of positivism is that the social world can be viewed as an external, objective reality and researchers working in this strategy attempt to give numerical values to social phenomena. Conversely, the main tenet of interpretivism is that the world is constructed through the meanings individuals attach to it through their experience in and interaction with their world. It is subjective in nature and researchers attempt to describe and understand social phenomena.

The positivist paradigm did not fit well with the aim of this research for three reasons. Firstly, the research aimed to provide an insight into "how" and "why" questions, i.e. an understanding of the way the ID model did and did not work. Secondly, the ID model and the application thereof could not be isolated from its organisational and social contexts, and perceptions about the user (i.e. learners' and managers') experiences of the ID model were integral to this. Thirdly, applying only a structured research methodology with pre-defined variables might overlook more subtle findings, which for the purposes of evaluating the ID model in an explorative sense were of importance in the research.

This research was therefore approached from and positioned in interpretivism, as interpretivism seeks to produce descriptive analyses explaining how individuals experience and interact with their world. Interpretivism holds that knowledge is derived from everyday concepts and meanings within context; the researcher enters this context and acts as the human instrument of data collection to grasp socially constructed meanings; and then reconstructs these meanings in a social scientific language. Data analysis is inductive, and aimed at gaining a holistic understanding of social phenomena, rather than defining sets of variables. 


\section{- $\quad$ Research tactic}

The choice of the case study tactic is based on the decision to "focus an enquiry around a specific instance or event" (Remenyi et al., 2002:50) - in this research the instance of the ID model in a specific organisation; "to provide a multidimensional picture of the situation" (Remenyi et al., 2002:51) - in this research the multi-dimensional picture as described by the multiple experiences of the users and other stakeholders of the ID model when implemented in the case organisation.

Yin (2003:5) points out that "how" and "why" research questions are likely to favour case studies, especially when the focus is on contemporary events (i.e. the ID model) and relevant behaviour (e.g. reactions to, perceived benefits of, rating of the components of the ID model) that cannot be manipulated. For this research, the case study tactic, using both qualitative and quantitative methods for data collection was employed.

A single-case design with multiple embedded units of analysis (EUA) was used. Single-case design is appropriate when the case is critical or unique; the phenomenon under study is previously unavailable; it is an exploratory study; and the case selected can be shown to be representative (Yin, 2003:45-50). The case selected for this research qualified on all these criteria. Within the single case, multiple embedded units of analysis (EUA) were included, not only to "add significant opportunities for extensive analysis” (Yin, 2003:46), but also to triangulate the findings and to rigorously explore all perspectives on the phenomenon under study. There were three EUAs in the case, namely EUA 1: learners, EUA 2: managers and EUA 3: training and specialist personnel.

The case organisation a fast moving consumer goods (FMCG) organisation that operates in diversified industries (tobacco growing, cigarette manufacture, packaging, product distribution) on an international basis and displays characteristics consistent with other international organisations, for example Adcock Ingram in the pharmaceutical industry; Parmalat in the dairy products industry; Heinz in the canned food industry. The relevance of these similarities is that single-case design is appropriate should the case selected be shown to be representative, as is the instance in this research. Also, where the case selected is shown to be similar to and representative of other organisations, "inductive generalisation" may be inferred (Mouton, 1996:80) and the exportability of the ID model to other organisations enhanced.

\section{Research programme}

This section outlines the research programme which includes the research methods, data analysis and integrity measures of the research.

\section{- $\quad$ Research methods}

In this research, both (a) quantitative and (b) qualitative research methods were applied within the case study. Mixed method research is seen to provide the answer to today's increasingly interdisciplinary, complex and dynamic research world (Johnson \& Onwueqhuzi, 2004:15). Therefore, researchers need to consider the value of mixing methods in order to create valuable research. Proponents of mixed methods research (see for example Hammersley, 2000; Bryman, 2001; Tashakkori \& Teddlie, 2003) hold that quantitative and qualitative methods are compatible and in real-world situations the methods (quantitative, qualitative or mixed methods) that work best should be used. What is important, is that no difference is made between the relative value of the methods, as the researcher looks at the findings as a whole, informed by the data obtained. The tendency is to look at "compound phenomena instead of a compartmentalization of variables, as in survey research" (Verschuren, 2003:130).

\section{a) Quantitative methods}

In order to obtain insight into how the ID model and its various components were rated (i.e. for quantification of data) by both learners and their managers, an ID model assessment questionnaire was applied. In developing the questionnaire used in the research, a review panel of five personnel at the case organisation provide a critique of the initial versions of the questionnaire, after completing it. Following three iterations of review and revision, the questionnaire was completed by a group of 10 learners to check for readability, usability and understanding. A fourpoint rating scale ${ }^{*}$ was used where 4 represented "excellent" and 1 represented "needs improvement".

Participants rated the main components (each with a number of specific descriptors) of the ID model, viz. its contents, text/written content, visual imagery; usability, process, system on electronic device; tasks, assessments. For the managers, a similar version was used, but additional ratings relating to their role as coaches and facilitators of the ID model were included.

Questionnaires were distributed to all regions via email, with a request to return completed questionnaires to the administering department within a specified time frame. A total of 167 (out of 377, i.e. 44\%) completed questionnaires were returned by learners, and a total of 31 (out of 60, i.e. $59 \%$ ) completed manager questionnaires were returned at the end of the specified cut-off period.

A second quantitative input to this research was obtained from the back-end technical learning management system that measured quantitative levels of job-specific knowledge before implementation of the ID model, and then again after implementation.

\footnotetext{
* Note: It is an HR practice in the case organisation to use this fourpoint rating scale with these definitions. This is to avoid responses in the middle, or neutral position. Since both learners and their managers are au fait with this rating scale in the organisation, it was also adopted for this research.
} 
b) Qualitative methods

Qualitative methods are ideally suited to explore attitudes, opinions, thoughts, reactions and feelings. For the purpose of this research, focus groups, researcher's notes and in-field direct observation were used. Augmenting these qualitative methods, additional evidence and data were collected from organisation documentation (for example, the ID model business case document, internal review documents and project plan documents); and conversations with expert personnel (for example contents experts, IT personnel).

Focus groups

For this study, a total of 10 focus groups was conducted, i.e. five with members of EUA 1 (i.e. learners) and five with members of EUA 2 (i.e. managers). The focus groups consisted of between $5-13$ participants and they were held at the offices of the case organisation in the various regions. All group sessions were transcribed and the transcripts form the raw data input. For EUA 3 (training and specialist personnel), a series of meetings were held.

\section{Researcher's notes}

Supplementary to the data obtained from the focus groups, meetings and organisation documentation, field notes made by the researcher both during and after the discussions, as well as transcripts and notes from meetings with training and specialist personnel and other key stakeholders at the case organisation were used in the data analysis.

\section{In-field direct observation}

Notes relating to hunches and observations made by the researcher in field were included in the data set, and formed part of the ongoing and final analysis and interpretation of the data. In addition, during the focus groups managers were asked about what they observed in practice, when learners were doing their in-field tasks.

All transcripts of the focus groups and meetings and the researcher's notes and notes from the in-field observation were used for the qualitative data inputs.

\section{- Data analysis}

In this research, the data sets from both the quantitative and qualitative methods provided the data input for analysis. The quantitative data set consisted of the rating (mean) of all components of the ID model and the measurement of jobspecific knowledge levels pre- and post implementation of the ID model. The qualitative data (transcripts from focus groups and meetings, researcher's notes, field notes, organisation documents) were coded and grouped together from both an inductive (moving from the data to themes) and deductive (moving from defined themes to the data) perspective. Data were hand-analysed since no funding was available for the purchase of computer-assisted software for qualitative data analysis; hand analysis also being the status quo in the South African marketing research industry. The coding for the qualitative data consisted of both a broad inductive coding frame (identifying all responses and the broad coding categories allocated to each) and a focused coding scheme (containing focused codes for the broad coding categories).

\section{- Integrity measures}

The integrity of the research was defined by the rigour, quality and trustworthiness of the methods used and dependability was demonstrated through exhaustive descriptions of the methods, coding and data analysis strategies and additional measures such as member checking and triangulation. The case bounds were identified both in terms of the profile of the case organisation (as an international FMCG organisation with traditional organisational structures and operating in seven regions in South Africa); and the time boundaries (i.e. stipulating when the data collection took place) of the case.

Researcher bias might be present in the researcher also being the developer of the ID model, however this was curtailed through various exacting integrity measures that were implemented. This included qualitative and quantitative methods; multiple sources triangulation; member checking with participants to provide verification of the interpretation of the data and to validate the researcher's interpretation, conclusions and reflections regarding the phenomenon under study. Particular attention was paid to negative case analysis, as this is one of the ways in which researcher assumptions and bias might be overcome. Specific rigour and quality $(\mathrm{R}+\mathrm{Q})$ measures were also incorporated to further augment and increase the integrity of the research. The $\mathrm{R}+\mathrm{Q}$ measures included the use of participants' voices (descriptive $\mathrm{R}+\mathrm{Q}$ ); availability of all transcripts and field notes (interpretive $\mathrm{R}+\mathrm{Q}$ ); using multiple theories and sources to provide the theoretical $\mathrm{R}+\mathrm{Q}$; providing a clear description of the sample and how it was achieved (internal $\mathrm{R}+\mathrm{Q}$ ); explaining coding frames and schemes clearly (criterion $\mathrm{R}+\mathrm{Q}$ ); achieving construct $\mathrm{R}+\mathrm{Q}$ by drawing on extended literature sources; choosing the sample in different locations and analytic transferability of the selected case organisation (external $\mathrm{R}+\mathrm{Q}$ ) and obtaining input from colleagues, academic staff and other experts ( $\mathrm{R}+\mathrm{Q}$ of design). In light of the above, integrity measures and rigour for this research were demonstrated.

\section{Research results, analysis and interpretation}

This section will firstly present the results from the quantitative methods, including the rating of the constituent parts of the ID model and the pre-post job-specific knowledge measures extracted from the back-end technical learning management system; secondly provide the results from the qualitative methods; and thirdly offer an analysis and interpretation.

\section{Results from quantitative methods}

The overall results from the quantitative methods indicated that the ID model obtained highly positive ratings on most of its constituent parts - see Table 1 to Table 4 . 
Table 1: Rating of learning contents of ID model

\begin{tabular}{|c|c|c|c|}
\hline Main contents components & Component mean & $\begin{array}{l}\text { Underlying } \\
\text { descriptors }\end{array}$ & $\begin{array}{c}\text { Mean } \\
\text { (out of 4) }\end{array}$ \\
\hline \multirow{3}{*}{ Contents overall } & \multirow{3}{*}{3.36} & Ease of understanding & 3,31 \\
\hline & & Relevancy to my job & 3,51 \\
\hline & & Interesting & 3,26 \\
\hline \multirow{3}{*}{ Text on visuals/written contents } & \multirow{3}{*}{3.31} & Ease of understanding & 3,28 \\
\hline & & Enhances learning & 3,33 \\
\hline & & Gives clear information & 3,33 \\
\hline \multirow{4}{*}{ Visual contents/imagery/pictures } & \multirow{4}{*}{3.23} & Explains contents further & 3,16 \\
\hline & & Enhances information given and learning & 3,24 \\
\hline & & Interesting & 3,20 \\
\hline & & Relevant & 3,30 \\
\hline
\end{tabular}

Table 2: Rating of usability of ID model

\begin{tabular}{c|c|l|c}
\hline Main component & $\begin{array}{c}\text { Component } \\
\text { mean }\end{array}$ & Underlying descriptors & $\begin{array}{c}\text { Mean } \\
\text { (out of 4) }\end{array}$ \\
\hline \multirow{4}{*}{ Usability } & \multirow{3}{*}{2.98} & Ease of finding the information I want or need & 2,87 \\
\cline { 3 - 5 } & & Ease of finding relevant tasks to contents sections & 2,95 \\
\cline { 3 - 5 } & & Instructions on how to use the programme & 2,98 \\
\cline { 3 - 5 } & & Ease of using the programme & 3,07 \\
\cline { 3 - 5 } & Ease of finding way around the learning material & 3,03 \\
\hline
\end{tabular}

Table 3: Rating of process of ID model

\begin{tabular}{c|c|l|c}
\hline Main component & $\begin{array}{c}\text { Component } \\
\text { mean }\end{array}$ & \multicolumn{1}{|c}{ Underlying descriptors } & $\begin{array}{c}\text { Mean } \\
\text { (out of 4) }\end{array}$ \\
\hline \multirow{3}{*}{ Process } & \multirow{3}{*}{3.09} & Clarity of six steps to be followed & 3,05 \\
\cline { 3 - 5 } & & Ease to understand how overall model works & 3,10 \\
\cline { 3 - 5 } & & Ease of getting contents installed & 3,05 \\
\cline { 3 - 5 } & & Ease of accessing learning system for assessments & 2,94 \\
\cline { 3 - 5 } & & Ease of submitting in-field tasks and getting sign-off & 3,31 \\
\hline
\end{tabular}

Table 4: Rating of in-field tasks and learning system assessment

\begin{tabular}{|c|c|c|c|}
\hline Main component & $\begin{array}{c}\text { Component } \\
\text { mean }\end{array}$ & Underlying descriptors & $\begin{array}{c}\text { Mean } \\
\text { (out of 4) }\end{array}$ \\
\hline \multirow{4}{*}{ In-field tasks } & \multirow{4}{*}{3.20} & Ease of completing in-field tasks & 3,15 \\
\hline & & Ease of submitting in-field tasks & 3,19 \\
\hline & & Ease of obtaining sign-off & 3,25 \\
\hline & & Ease of obtaining coaching inputs & 3,20 \\
\hline \multirow{4}{*}{ Learning system } & \multirow{4}{*}{3.15} & Ease of arranging via manager's PC & 3,14 \\
\hline & & Ease of getting access & 2,99 \\
\hline & & Format of assessments & 3,13 \\
\hline & & Obtaining scores & 3,32 \\
\hline
\end{tabular}


The learning contents of the ID model were rated positively in terms of its ease of understanding, relevancy to the job at hand and being interesting. The text or written contents were rated positively on ease of understanding, enhancing learning and giving clear information. Similarly, the visual contents or imagery were rated positively on explaining the learning contents further, enhancing both the information given and learning, and being interesting and relevant.

To a degree, the results relating to usability should be viewed against the background of the computer literacy levels of the learner audience. At the time of the research, learners were just introduced to laptops and they were consequently not particularly computer literate to the degree where they could comfortably find their way through a both a new computer and a new programme.

The process of the ID model and its underlying descriptors relating to the clarity of the six steps to be followed, the ease of understanding how the ID model works, the ease of getting the contents installed and the ease of submitting infield tasks and getting sign-off all rated positively. A slightly lower rating was obtained for "ease of accessing learning system for assessments" which may be explained by the fact that access to the learning system for the learners was via the managers' PCs and learners were thus dependent on time availability from the managers.
The in-field tasks, learning system and their underlying descriptors were rated positively, with the possible exception of "ease of getting access" relating to the learning system. For the in-field tasks ease of completing, submitting and obtaining sign-off was rated positively, as was the ease of obtaining facilitation (coaching) inputs. For the learning system the format of assessments and obtaining scores was positive, as was “ease of arranging via manager's PC”. This seems at odds with other results, however, "ease of getting access" was rated at a relatively lower level. It may therefore be surmised that while it might be easy to arrange access to the learning system per se, it might not always be easy for learners to actually get the time to gain access via the manager's PC.

Overall, the performance of the ID model was judged to achieve both the success criteria defined by the organisation and the action standards of the research. All the components of the ID model and its usability were rated positively and it was felt that, through the way the ID model worked, learners could apply knowledge in practice, and this helped to entrench positive behaviour which added to productivity and ultimately set the organisation apart in its service offering in the market.

Table 5 reflects the learning system pre-post ID model implementation job-specific knowledge measures.

Table 5: Learning system pre-post ID model implementation job-specific knowledge measures

\begin{tabular}{|c|c|c|c|c|}
\hline Courses & $\begin{array}{c}\mathrm{N} \\
(\text { Total }=\mathbf{3 1 8})\end{array}$ & $\begin{array}{c}\text { Pre-measure } \\
\text { Average score } \\
\% \\
\end{array}$ & $\begin{array}{c}\text { Post-measure } \\
\text { Average score } \\
\% \\
\end{array}$ & $\begin{array}{c}\text { Increase } \\
\text { or decrease }\end{array}$ \\
\hline Introductory skills range & 304 & 85 & 91 & +6 \\
\hline Job-specific skills range & 288 & 87,5 & 94,5 & +7 \\
\hline Skills range 1 & 250 & 81 & 91,5 & $+10,5$ \\
\hline Skills range 2 & 15 & 71 & 90 & +18 \\
\hline Skills range 3 & \multicolumn{4}{|c|}{ Not completed by any learners } \\
\hline \multicolumn{5}{|l|}{ Measure 2 (August 2007) } \\
\hline Courses & $\mathbf{N}$ & $\begin{array}{c}\text { Pre-measure } \\
\text { Average score } \\
\% \\
\end{array}$ & $\begin{array}{c}\text { Post-measure } \\
\text { Average score } \\
\% \\
\end{array}$ & $\begin{array}{c}\text { Increase } \\
\text { or decrease }\end{array}$ \\
\hline Introductory skills range & & \multicolumn{3}{|c|}{ Considered complete } \\
\hline Job-specific skills range & 302 & 86,3 & 95,1 & $+8,8$ \\
\hline Skills range 1 & 295 & 86 & 93,8 & $+7,8$ \\
\hline Skills range 2 & 38 & 80 & 94,0 & +14 \\
\hline Skills range 3 & 21 & 73 & 92,5 & $+19,5$ \\
\hline
\end{tabular}

At measure 1 , there was a +6 increase in job-specific knowledge pre- and post ID model implementation for the introductory skills range; a +7 increase for the job-specific skills range; and a +10.5 increase for skills range 1 . At the time of this measure only 15 learners had completed skills range 2 and a +18 increase in job-specific knowledge was shown. At measure 2, with more learners having completed the various courses, there was a +8.8 increase in the jobspecific knowledge in the specific skills range, a +7.8 percent in skills range 1 , a +14 in skills range 2 and a +19.5 in skills range 3 , albeit that the number of learners who had completed skills ranges 2 and 3 was still low, due to the compulsory skills range completion being skills range 1 .

These increases were deemed as being satisfactory by stakeholders at the case organisation, as it showed that the ID model did bring about measurable increases in jobspecific knowledge, thus addressing one of its main aims. 


\section{Results from qualitative methods}

The results from the qualitative methods may be summarised under reactions to the ID model specifically; likes and dislikes; and benefits.

\section{- $\quad$ Reactions to ID model specifically}

The ID model specifically was described as containing comprehensive and relevant learning contents, which helped learners in knowing more about their jobs and their organisation. The ID model was seen to be conducive for improving both job-specific knowledge and the application thereof in practice, so that people "become better at their jobs" (i.e. improved productive behaviour). The ID model was described as being very user-friendly and easy and simple to understand.

\section{- $\quad$ Likes and dislikes}

The likes of participants centred around four main themes, outlined below.

First theme: participants liked the practical, on-the-job skills and job-specific knowledge imparted through the ID model, as this was seen to appreciably improve how daily tasks onthe-job were completed. Also, since a bigger understanding was obtained on the "why" of doing certain things, participants felt more inclined to "do it that way". Furthermore, the practical application of the theory through the in-field tasks was experienced positively, judged to "show you how to apply your knowledge" and seen to enhance the entrenching of "best practices".

Second theme: participants liked the learning contents and innovative nature of how the contents are presented, i.e. the combination of an illustrative and graphic visual learning language supporting, enhancing and complementing the text.

Third theme: participants liked the way they were empowered through the "self-learning which creates a learning culture" and "it is for self development and helping my career".

Fourth theme: participants felt the ID model and the jobspecific, organisation and industry knowledge and learning imparted through it provided them with an edge in the market, as it enhanced practical knowledge based on relevant information.

The ID model was seen to be conducive for improving both job-specific knowledge and the application thereof in practice, so that people "become better at their jobs" (i.e. improved productive behaviour). The ID model was described as being very user-friendly and easy and simple to understand.

There were no dislikes of the ID model per se, however other considerations pertaining to the organisation climate and operational procedure at the time impacted somewhat on reactions. These other considerations related by and large to the lack of time due to pressures from other organisational activities; the perception that managers were not skilled, knowledgeable, experienced or interested enough to fulfil their roles in the ID model adequately; and the lack of recognition in that learners did not, at that time, receive any form of accreditation, whether formal or informal, on the completion of courses.

\section{- $\quad$ Benefits}

The benefits of the ID model were linked to the likes about the ID model and included "learning by doing", seen to enhance and entrench job-specific knowledge and relevant behaviour ("it is practical and geared to show us how to do things in the correct way); and the benefit of attaining insight into the organisation and its business on a broader level ("I have the frame of reference of my job. It gives a line of sight of what we have to do, not only what, but how and why. And how to be better at our business in the market”). Self-paced learning was seen to be of benefit as less out-of-field time for learning was needed ("No out-offield time, it's always accessible and job principles are applied constantly".)

\section{Analysis and interpretation}

A combination of the results from the quantitative methods and the results from the qualitative methods provides the basis for the analysis and interpretation.

Reactions to the ID model were positive with both learners and managers being well disposed to the ID model. It was felt that, through the learning facilitated by the ID model, learners were more knowledgeable about their jobs and could do their jobs better. It was felt that the practical application of job-specific knowledge reinforced learning and improved productive behaviour in both core and situation-specific situations in the value chain of the organisation. The pre-post ID model implementation measure of job-specific knowledge, showed, at two measure points in time, average increases in job-specific knowledge of 11 percent pre-post ID model implementation. These increases are noteworthy for this research, since job-specific knowledge was seen as one of the proxies for improving productive behaviour that ultimately influenced organisational capabilities and core competencies for SCA. The quantitative impact of the ID model on productive behaviour was not directly measured in the rating of the components of the ID model, as it was seen to be a qualitative property to be assessed through observation and an interpretation of attitudes, feelings and opinions relating to reactions to the ID model, as further investigated and explored in the qualitative methods.

From this exploratory and interpretive research, there were five main reasons why and how the ID model was seen to positively contribute to learning and the improvement of job-specific knowledge and productive behaviour. First, the self-paced, "learning by doing" design of the ID model was seen to contribute positively to why the ID model worked. Second, the relevance of the learning contents to the specific organisation and the specific jobs of learners caused the ID model to be seen as making a positive contribution to relevant learning and job-specific knowledge was 
measurably increased. Third, because of the organisationand job-specific contents, the ID model was seen to impact positively on organisation-relevant productive behaviour, and the application thereof in practice, when servicing customers. Fourth, the ID model was seen as an easy-to-use system, which allowed easy access to learning contents and clear instructions on the processes to be followed. Lastly, reaction to the ID model was positive, i.e. learners liked it and preferred it to previous training practices, as it was seen to be empowering and the way of the future.

\section{Conclusions and assessment of research}

From the results, analysis and interpretation the following overall conclusions may be inferred:

- The ID model impacts positively on job-specific knowledge and productive behaviour, and therefore human capital in the organisation is improved. Through this improvement in job-specific knowledge and productive behaviour, the ID model is a tool that can be used to reconfigure resources to the benefit of the organisation.

- The change in training practices, in the instance of this research specifically through the development and implementation of a revised ID model aimed at increasing organisation capabilities and improving organisation competencies, enables the organisation to provide a better service and differentiate itself.

- Therefore, on the basis of this exploratory and interpretive research, the ID model may be viewed as an enabler for SCA for the case organisation for which it was developed and in which it was implemented.

The ID model put forward in this research, as a revised and extended ID model to provide strategically relevant training within the organisation, was seen to bring about a measurable increase in job-specific knowledge and a reported improvement in productive behaviour, in both core and situation-specific instances. In light of the South African context, ID models that aid in "learning by doing" and thus provide measurable increases in job-specific knowledge and the productive behaviour facilitated through increased understanding and on-the-job application of knowledge and skills may be seen, as also evidenced in the literature, to contribute to a more productive workforce. A productive workforce is one of the facilitators of improving organisational performance that in turn impact on economic growth rates, decreases in unemployment and the social well being of citizenry in the country.

The results corroborate the positive linkage between improved job-specific knowledge and productive behaviour, which, as in the RBV literature; serve as enablers for SCA through improvements in organisational capabilities and core competencies. The research results plausibly suggest that the ID model as put forward in this research may offer a revised value-added ID model for organisational training that positively increases job-specific knowledge and productive behaviour, and by proxy, SCA for the organisation. From both an organisational and a South
African perspective, this is meaningful in that skills development is on the national agenda as a major priority. The ID model as presented offers an alternative to many current training practices that are considered to be inadequate and not conducive to fast tracking skills development. As a viable alternative, it may be applied and implemented to the benefit of the workforce, other organisations and ultimately the country.

In this research, the ID model was judged to be effective in enhancing and improving job-specific knowledge which was applied successfully on-the-job and consquently resulted in improved core- and situation-specific (productive) behaviour. The results also positively indicated that, through the job-specific knowledge imparted by the ID model, the organisation attained an advantage amongst customers by providing a better and more knowledgeable service. These results are consistent with the literature and thus support and confirm the broad premise that there is a positive linkage between the development of human capital through training and SCA. Therefore, it may reasonably be surmised that the results from this research may be seen to be transferable and the ID model exportable to other organisations. In the South African context, with the development of skills (delineated in this research as job-specific knowledge and productive behaviour) as a priority on the national agenda, this ID model was seen to offer a viable alternative to existing and underperforming ID models.

However, more research will be required to put quantitative values to the degrees of improvement in both core and situation-specific behaviour brought about by the ID model if this linkage is to be precisely delineated. Also, additional research that may add further value to this research include:

- A longitudinal and comparative evaluation of the value of this ID model compared to existing (other) training practices in organisations as pertaining to increased jobspecific knowledge and productive behaviour may provide supplementary and generalisable substantiation and corroboration of the exploratory and interpretive results of this research.

- The implementation and evaluation of the ID model in other organisations - both of a similar type as the case organisation in this research and other types of organisations.

- Regarding the transferability of the ID model to the public sector, it is recommended that the applicability and performance of the ID model in the public sector be investigated. Management in the public sector has been undergoing a major metamorphosis since Hood (1991) first referred to "New Public Management". With this as benchmark it has been noted that the public sector in Africa needs a "customer-orientated civil service, (which) requires an attitudinal-focused training (programme" (Economic Commission for Africa, 2003:43). In South Africa in particular, Kamoche observes that it is doubtful if training in the public sector has so far led to any noteworthy organisational performance, lacking both knowledge and skills (Kamoche, 1997:268). 
The results, as is consistently presented in RBV discourse and the impact of training on productive behaviour as the sources for organisational performance, corroborate the effect of the development of job-specific knowledge and relevant productive behaviour on the positive performance of the workforce which ultimately benefits the organisation. The research thus showed consistency with and extended the literature through its positioning in business-level strategy and expounding on the link between training (through the ID model) and SCA for organisations.

Fundamentally, it is suggested that the ID model put forward in this research, and ratified by the results, contributed to knowledge and theory by using a multidisciplinary approach to provide an extended and broader ID model that measurably increases job-specific knowledge and is seen to improve the application of this job-specific knowledge and related skills in productive behaviour. The ID model put forward in this research may be seen to offer an alternative to outdated and largely inadequately performing training practices. Although further research is required, this research offered a blueprint for an ID model to serve as an enabler for sustainable competitive advantage.

\section{Summary}

Pervasive, ongoing change places new demands on organisations and the business-level strategies they employ to achieve SCA. One of the ways to achieve SCA is through the development of a productive, skilled and competent workforce. Human resource development, specifically through training, increasingly needs to cultivate job-specific knowledge and productive behaviour to develop and build a competent and productive (skilled) workforce. In the South African context, the focus on fast-tracking skills development is on the national agenda as one of the top priorities for the country. Training, through the ID models it employs, is facing increasing demands to align with the strategic intent and business strategies of organisations (and by inference, countries) to increase relevant job-specific knowledge (and skills) that contribute, through improved productive behaviour, to organisation capabilities and core competencies as sources for SCA.

This research presented an ID model for organisation training aimed at improving job-specific knowledge and productive behaviour. It was put forward in light of a changing and turbulent business environment and defined shortcomings of current training practices. It positioned the ID model as an enabler for sustainable competitive advantage through being a tool to positively impact on organisation capabilities and competencies vested in human capital.

The ID model was evaluated through exploratory interpretive research conducted within a case organisation in which the ID model was implemented. Reaction to the ID model was positive and it was seen to enhance the productive behaviour required to enable the workforce to provide a more informed and better service. The ID model quantitatively increased job-specific knowledge, a further requirement for improving productive behaviour. The ID model and its positive improvement of job-specific knowledge were seen to be particularly applicable in and relevant for the improvement of productive behaviour. The ID model and its positive impact on productive behaviour through the application of job-specific knowledge and improved perceived professionalism in the market was demonstrated quantitatively and confirmed qualitatively. A key tenet of this research was contained in the constructs of job-specific knowledge and productive behaviour being improved through training and the ID models employed, and the contribution of job-specific knowledge and productive behaviour to organisational capabilities and core competencies, which in turn contribute to SCA.

The research confirmed the contribution of the ID model in improving job-specific knowledge and productive behaviour and described and substantiated the pivotal link between training and ID models and the application thereof in practice to aid organisations in the achievement and sustainability of competitive advantage.

\section{References}

Bassi, L.J., Benson, G. \& Cheney, S. 1996. 'The top ten trends', Training and Development, 50(11):28-42.

Boyle, M.A. \& Crosby, R. 1997. 'Academic program evaluation: Lessons from business and industry', Journal of Industrial Teacher Education, 34(3):81-85.

Bryman, A. 2001. Social research methods. Oxford: Oxford University Press.

Burrel, B. \& Morgan, G. 1979. Sociological paradigms and organisational analysis. United Kingdom: Heinemann.

Denzin, N.K. \& Lincoln, Y.S. (Eds). 1994. Handbook of qualitative research. Thousand Oaks, CA: Sage Publications.

Economic Commission for Africa. 2003. Public sector management reforms in Africa. Development Policy management Division (DPMD), Addis Ababa, Ethiopia. Addis Ababa: ECA.

Guba, E.G. 1985. 'The context of emergent paradigm research'. In Lincoln, Y.S. (Ed). Organisational theory and inquiry: The paradigm revolution. U.K: Sage.

Hammersley, M. 2000. 'Varieties of social research: A typology', The International Journal of Social Research Methodology: Theory and Practice, 3(3):221-231.

Hesse-Biber, S.N. \& Leavy, P. 2004. Approaches to qualitative research. A reader on theory and practice. New York: Oxford University Press.

Hood, C. 1991. 'A public management for all seasons', Public Administration, 69(Spring):3-19.

Hussey, J. \& Hussey, R. 1997. Business research. A practical guide for undergraduate and postgraduate students. London: MacMillan Press. 
Johnson, R.B. \& Onwueghuzi, A.J. 2004. 'Mixed methods research: A research paradigm whose time has come', Educational Researcher, 33(7):14-26.

Kamoche, K. 1997. 'Competence-creation in the African public sector', International Journal of Public Sector Management, 10(4):268-278.

Kirkpatrick, D. 1994. Evaluating training programs. San Francisco, CA: Berrett-Koehler Publishers Inc.

Kirkpatrick, D. 1996. 'Great ideas revisited', Training and Development Journal, 50(1):54-59.

Mouton, J. 1996. Understanding social research. Pretoria: JL van Schaik Academic.

Remenyi, D., Williams, B., Money, A. \& Swartz, E. 2002. Doing research in business and management. An Introduction to process and method. London: Sage Publications.

Tashakkori, A. \& Teddlie, A. 2003. Handbook of mixed methods in social and behavioural research. London: Sage.

Verschuren, P.J.M. 2003. 'Case study as a research strategy: Some ambiguities and opportunities', Int. J. Social research Methodology, 6(2):121-139.

Yin, R.K. 2003. Case study research. Design and methods. ( $3^{\text {rd }}$ Edition). Thousand Oaks, California: Sage Publications, Inc. 